\title{
The evaluation of a patient with dizziness
}

Kevin A. Kerber, MD

Robert W. Baloh, MD

\section{Summary}

Dizziness is the quintessential symptom presentation in all of clinical medicine. It can stem from a disturbance in nearly any system of the body. Patient descriptions of the symptom are often vague and inconsistent, so careful probing is essential. The physical examination is performed by observing the patient at rest and following simple movements or bedside tests. In general, no special tools are required. The causes of dizziness range from benign to life-threatening disorders, and features that distinguish among these may be subtle. When diagnostic testing is considered, parsimony should be the rule. Identifying common peripheral vestibular disorders is a priority. Picking this "low hanging fruit" can be the key component to excluding more serious central causes of dizziness.

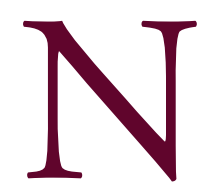

eurologists play an important role in the evaluation and management of patients with dizziness. The possibility of a serious neurologic disorder is unnerving to front-line physicians who have ranked decision support for identifying central causes of vertigo as a top priority. ${ }^{1}$ Although dangerous cen-

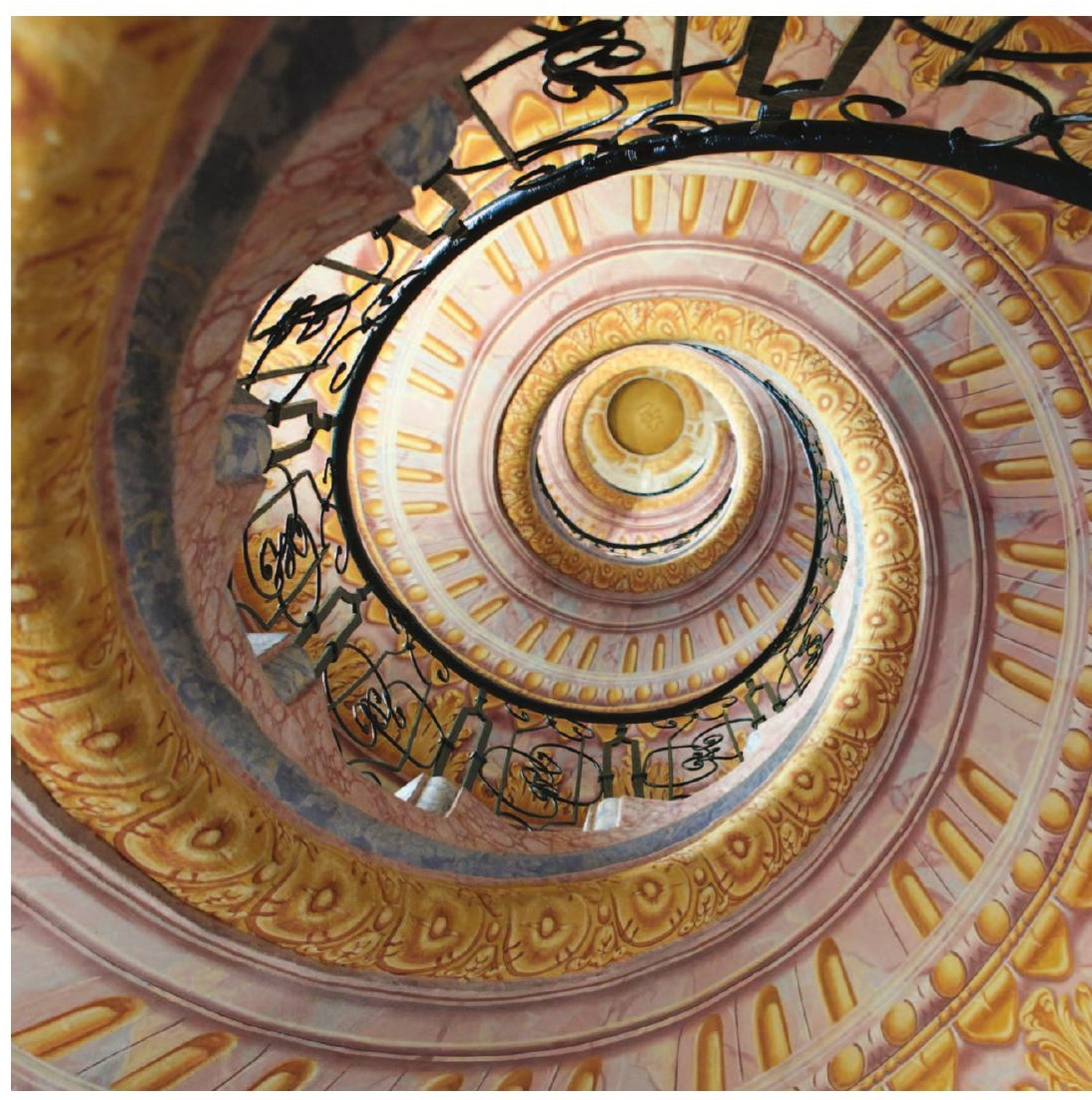
tral disorders do not commonly present as isolated dizziness, stroke and other neurologic disorders can occur in this manner. The history and physical examination are the critical elements in determining the management of these patients. In this article, we review the approach to the evaluation and management of patients with dizziness.

\section{History}

The first step in assessing a patient presenting with dizziness is to define the symptom (table 1). The patient's report is subjective and thus can be unreliable and inconsistent. ${ }^{2}$ For example, vertigo, defined as an illusion of movement, indicates an imbalance within the vestibular system. However, just because a patient reports "vertigo" does not mean that the cause is a

Department of Neurology (KAK), University of Michigan Health System, Ann Arbor; and Departments of Neurology and Surgery (Head and Neck) (RWB), David Geffen School of Medicine at UCLA, Los Angeles.

Correspondence to: kakerber@umich.edu 
Table 1 Common types of dizziness symptoms

\begin{tabular}{|c|c|}
\hline Descriptions & Common causes \\
\hline $\begin{array}{l}\text { Vertigo (e.g., visualized spinning, tilting, } \\
\text { dropping of the environment) }\end{array}$ & $\begin{array}{l}\text { Imbalance in tonic vestibular signals due to } \\
\text { unilateral peripheral or central lesion }\end{array}$ \\
\hline Lightheaded/woozy & $\begin{array}{l}\text { Blood pressure, metabolic, drugs, } \\
\text { vestibular, psychophysiological }\end{array}$ \\
\hline Near-faint & Decreased cerebral blood flow (diffuse) \\
\hline $\begin{array}{l}\text { Out of body, floating, spinning inside } \\
\text { (e.g., no visualized movement of the } \\
\text { environment) }\end{array}$ & Psychophysiological \\
\hline Motion sickness or intolerance & Sensory conflict \\
\hline Gait unsteadiness & $\begin{array}{l}\text { Loss of vestibular, proprioceptive, } \\
\text { cerebellar, or motor function }\end{array}$ \\
\hline
\end{tabular}

vestibular disorder; similarly, just because a patient denies vertigo does not mean that a vestibular disorder is excluded. Even patients with obvious vestibular nystagmus during caloric testing may deny vertigo, and instead report a feeling of lightheadedness, "wooziness," or disorientation. Lightheadedness is a very nonspecific type of dizziness. When accompanied by a near-faint symptom, it is suggestive of diffuse decreased cerebral blood flow, such as occurs with cardiac arrhythmia or orthostatic hypotension. But lightheadedness also occurs with anxiety, metabolic derangements, drug intoxication, and vestibular disorders. Some patients describe their dizziness as an out-of-body experience, floating, or an internal spinning sensation (i.e., no visualized spinning of the environment). These descriptions suggest a psychophysiological symptom (i.e., a combination of psychiatric factors and physiologic responses such as hyperventilation or neurotransmitter release). Some patients, particularly patients with migraine, are chronically sensitive to motion (self and surround). Genetic factors presumably are important but the mechanism is unknown. Disequilibrium refers to a sense of unsteadiness when standing or walking and is a common accompanying symptom of vertigo or lightheadedness.

Because symptoms are subjective, defining the characteristics (e.g., onset, triggers, duration) of the symptom may be more important than defining the actual symptom (table 2). Patients tend to be more reliable and consistent with this information ${ }^{2}$ which is critical to formulating the differential diagnosis. The key characteristics include the onset date, whether it is constant or episodic, the duration, the triggers, any aggravating or alleviating factors, or any other patterns associated with the symptom.

\section{Examination}

The general examination should focus on the cardiovascular system including cardiac rhythm and orthostatic blood pressure measurements. The neurologic examination focuses on oculomotor function and balance.

\section{Spontaneous and gaze-evoked nystagmus}

In primary gaze, the most common oculomotor abnormality observed in patients with dizziness is spontaneous nystagmus. Finding spontaneous nystagmus indicates an imbalance within the central or peripheral vestibular system. A unidirectional horizontal spontaneous nystagmus (e.g., a spontaneous left-beating nystagmus that does not convert to right-beating on gaze testing to the right) is characteristic of an acute peripheral vestibular imbalance, but this pattern can also occur in lesions of the central vestibular pathways. Spontaneous vertical or pure torsional nystagmus indicates a central lesion.

After observing for spontaneous eye movements in primary gaze, next observe eye movements during and after gaze in each direction. "End gaze" nystagmus, which occurs variably in 
Table 2 Clinical features, diagnosis, and treatment of common causes of dizziness

$\begin{array}{lllll}\text { Disorder } & \text { Duration } & \text { Triggers } & \text { Diagnosis } & \text { First-line treatments }^{\text {a }} \\ \text { BPPV } & \text { Seconds } & \text { Turning in bed, } & \text { Upbeating-torsional } & \text { Canalith repositioning } \\ & & \text { reaching top shelf } & \begin{array}{l}\text { nystagmus on the Dix- } \\ \text { Hallpike test }\end{array} & \text { maneuver }\end{array}$

$\begin{array}{llll}\begin{array}{l}\text { Vestibular } \\ \text { neuritis }\end{array} & \text { Days to weeks } & \text { Usually spontaneous } & \text { Spontaneous unidirectional Symptomatic, } \\ & \text { horizontal nystagmus, corticosteroids, physical } & \text { corresponding positive } \\ & \text { head thrust test } & \text { therapy }\end{array}$

\begin{tabular}{|c|c|c|c|c|}
\hline $\begin{array}{l}\text { Ménière } \\
\text { syndrome }\end{array}$ & Hours & Sodium intake & Fluctuating hearing loss & Restrict salt, diuretic \\
\hline $\begin{array}{l}\text { Migraine- } \\
\text { associated } \\
\text { dizziness }\end{array}$ & Minutes-days & $\begin{array}{l}\text { Stress, lack of sleep, } \\
\text { diet }\end{array}$ & $\begin{array}{l}\text { Personal or family history of } \\
\text { migraine headaches; other } \\
\text { associated migrainous } \\
\text { symptoms }\end{array}$ & $\begin{array}{l}\text { Lifestyle factors, migraine } \\
\text { prophylactic medications }\end{array}$ \\
\hline
\end{tabular}

Stroke Days to weeks Usually spontaneous
Central nystagmus,
negative head thrust test,
other neurologic signs or

Stroke management symptoms

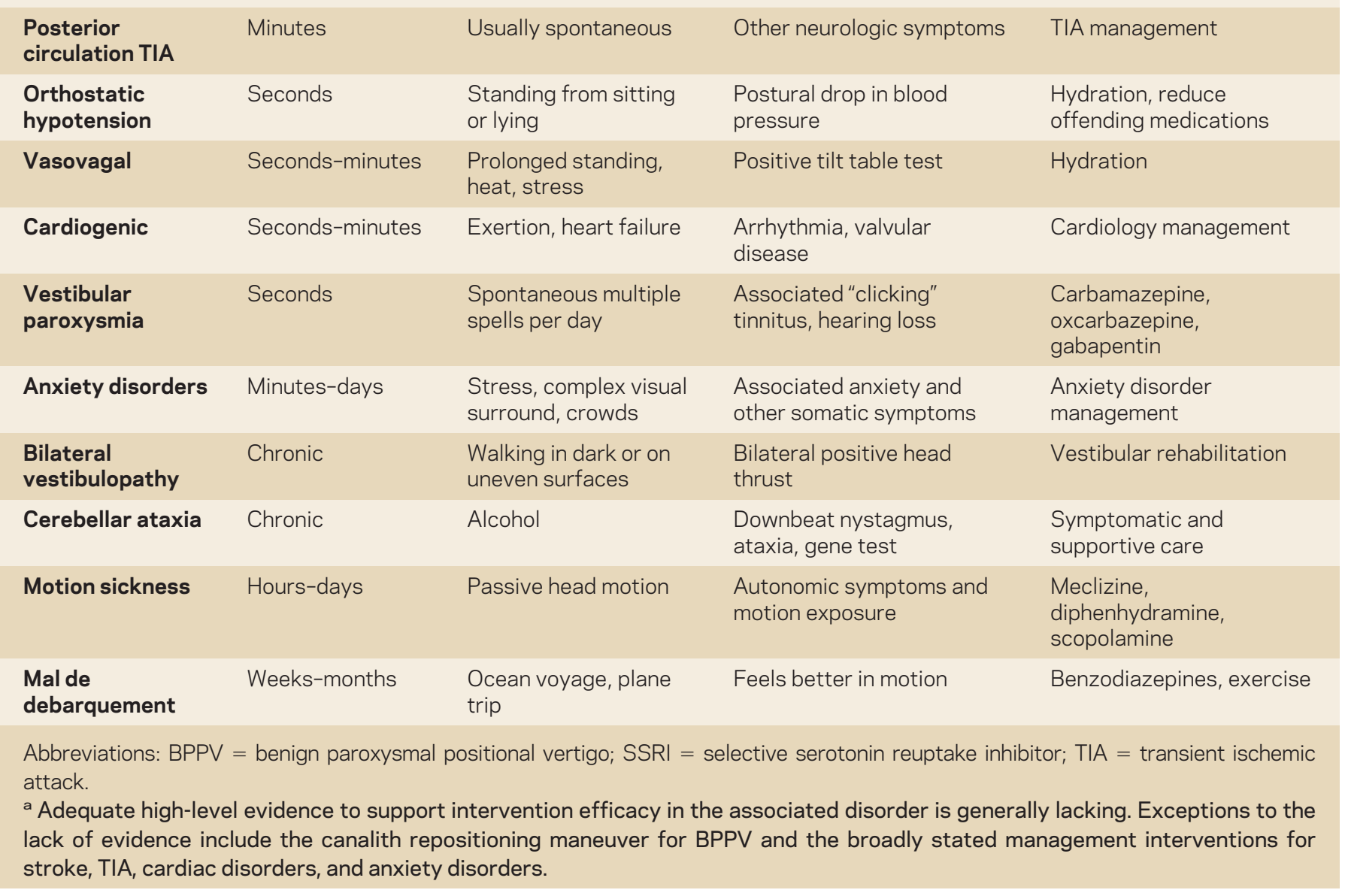

normal subjects, is the term used to describe a few beats of nonsustained and symmetric nystagmus with gaze more than 30 degrees off center. Conversely, persistent nystagmus that occurs when looking about 30 degrees to the side, "gaze-evoked" nystagmus, is a pathologic finding. A partially compensated unilateral vestibular lesion (e.g., vestibular neuritis) can result in gaze-evoked nystagmus that only occurs in one direction (for example, left-beating gaze-evoked nystagmus does not convert to right-beating nystagmus on right gaze). Central lesions typically lead to gaze-evoked nystagmus that is "bidirec- 


\section{Figure 1 The head thrust test}
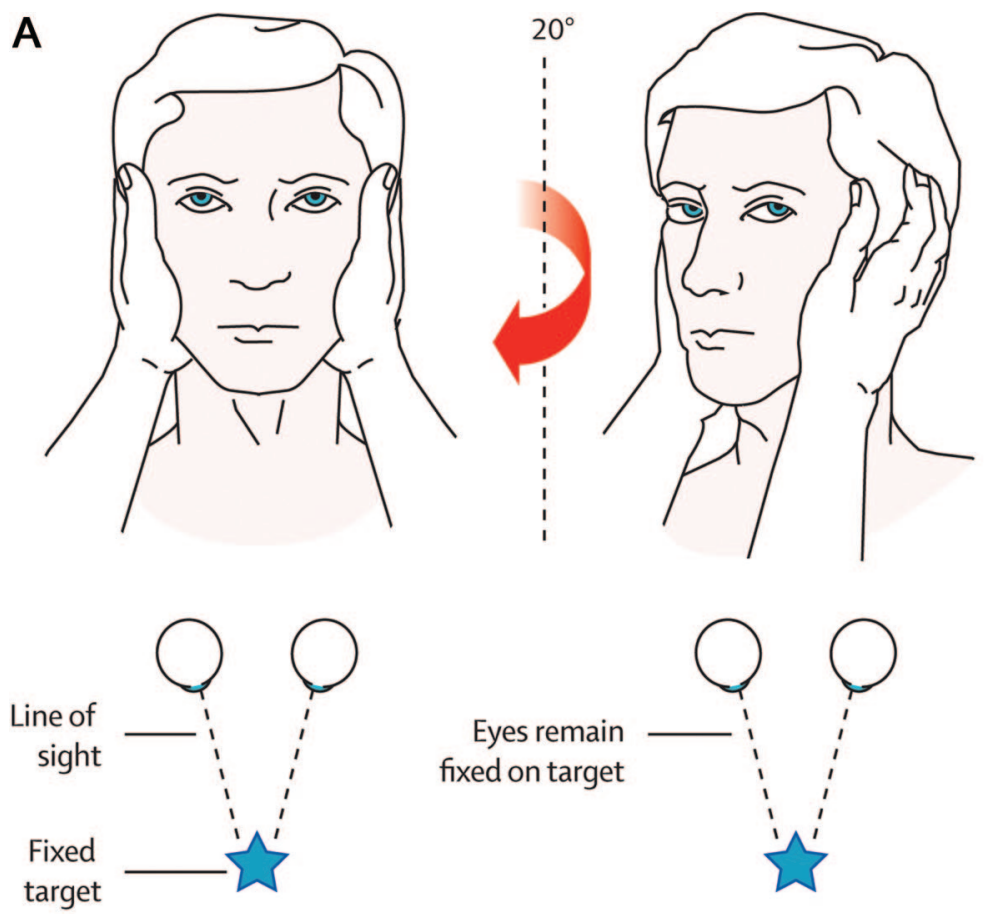

B
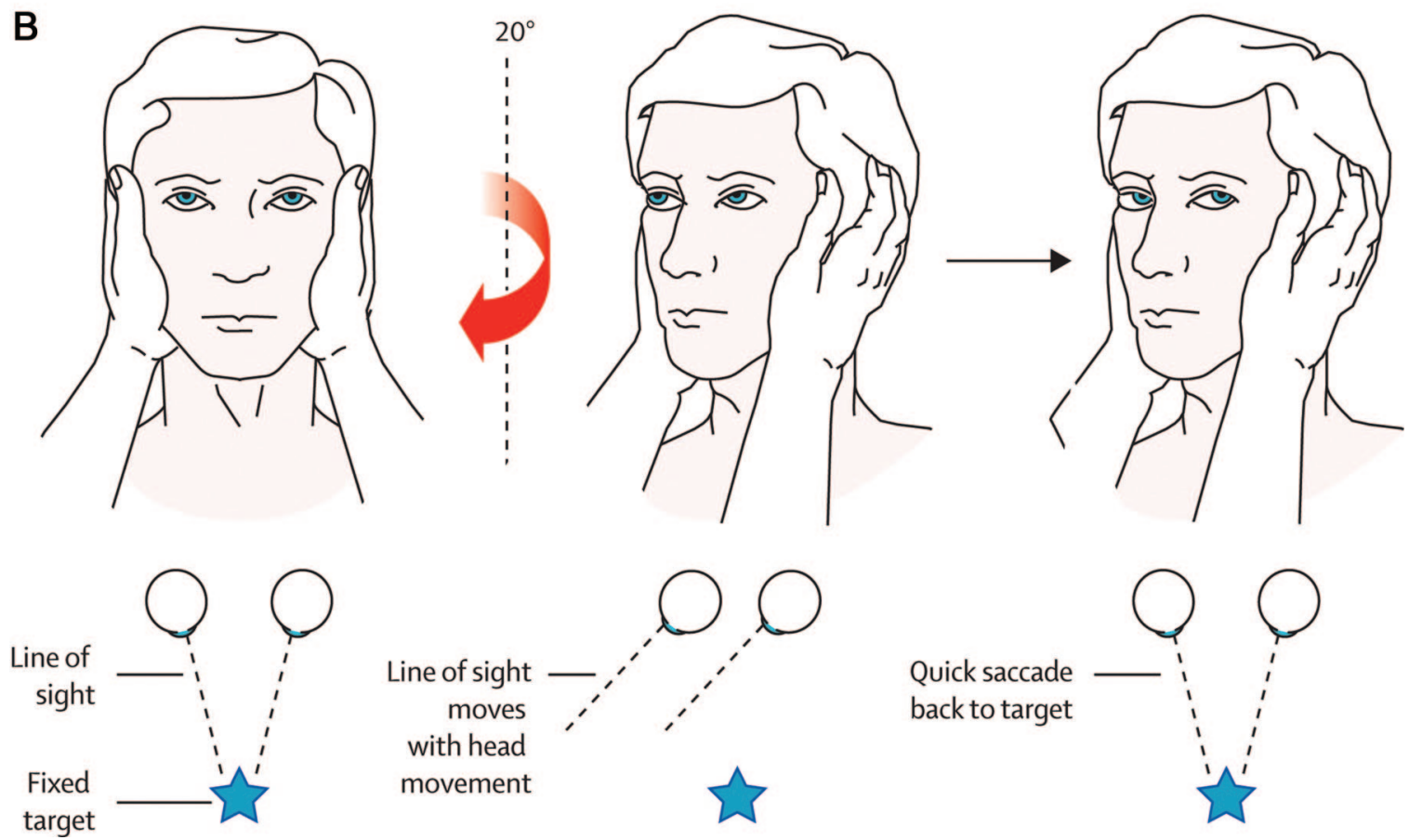

The head thrust test is a test of vestibular function that is performed as part of the bedside examination. This maneuver tests the vestibulo-ocular reflex (VOR). The patient sits in front of the examiner and the examiner holds the patient's head steady in the midline. The patient is instructed to maintain gaze on the nose of the examiner. The examiner then quickly turns the patient's head about 10-15 degrees to one side and observes the ability of the patient to keep the eyes locked on the examiner's nose. Note that the test can also be performed by starting with the head turned to the side, and then making the quick movement back to the midline. If the patient's eyes stay locked on the examiner's nose (i.e., no corrective saccade) (A), then the peripheral vestibular system is assumed to be intact. Thus in a patient with acute dizziness, the absence of a corrective saccade suggests a CNS localization. If, however, the patient's eyes move with the head (B) and then the patient makes a voluntary eye movement back to the examiner's nose (i.e., corrective saccade), then this suggests a lesion of the peripheral vestibular system and not the CNS. When a patient presents with the acute vestibular syndrome, the test result shown in A would suggest a CNS lesion, whereas the test result in B would suggest a peripheral vestibular lesion (thus, vestibular neuritis). From: Edlow JA, Newman-Toker DE, Savitz SI. Diagnosis and initial management of cerebellar infarction. Lancet Neurol 2008;7:951-964. 


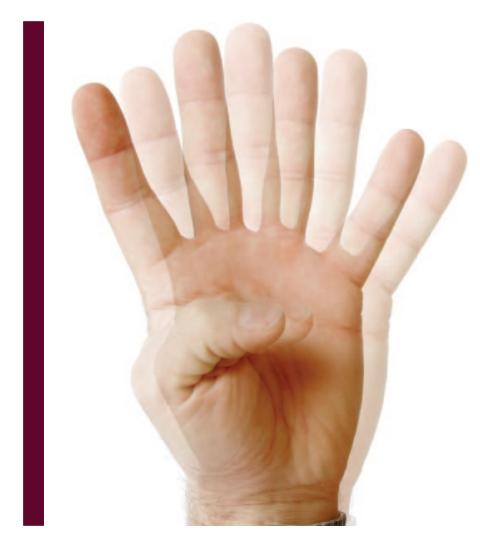

\section{Patients who present with new-onset severe dizziness, imbalance, and nausea and vomiting are especially challenging because serious neurologic causes such as brainstem and cerebellar stroke must be considered.}

tional" (i.e., left-beating nystagmus on left gaze, and right-beating nystagmus on right gaze) or vertical (i.e., upbeat on upgaze, downbeat on downgaze, or downbeat on side gaze).

\section{Bedside vestibulo-ocular reflex assessment}

The head thrust, or head impulse, test is used to assess the vestibulo-ocular reflex (VOR), and can uncover a unilateral or bilateral vestibulopathy at the bedside (figure 1). To perform the head thrust test, the physician stands directly in front of the patient seated on the examination table. The patient's head is held in the examiner's hands and the patient is instructed to focus on the examiner's nose. The head is then quickly moved about 10-15 degrees to one side. In patients with normal vestibular function, the VOR results in movement of the eyes in the direction opposite the head movement. This occurs very quickly such that the patient's eyes remain on the examiner's nose at all times during and after the sudden movement. The test is repeated in the opposite direction. Impairment of the VOR is identified when the eyes move off the target and a voluntary saccade (so-called refixation saccade) is observed bringing the patient's eyes back to the target after the head thrust test.

\section{Positional testing}

Positional testing can trigger peripheral or central nystagmus. The Dix-Hallpike test is used to diagnose the posterior semicircular canal variant of benign paroxysmal positional vertigo (BPPV) (figure 2, steps 1 and 2). With the patient sitting, the head is turned 45 degrees to the side placing the posterior canal on that side in the sagittal plain. The patient is then moved to the head-hanging position. If the patient has debris moving in the posterior canal, this will lead to a very specific pattern of nystagmus: a burst of upbeat-torsional nystagmus lasting about 15 seconds. Pure vertical nystagmus, particularly persistent downbeat nystagmus, suggests a central lesion, usually involving the midline cerebellum. If the Dix-Hallpike test is applied to a patient with vestibular neuritis, then the spontaneous unidirectional horizontal pattern of nystagmus will be accentuated. This "positional nystagmus" leads some clinicians to erroneously diagnose BPPV in patients with vestibular neuritis. To diagnose the horizontal canal variant of BPPV, the patient lies supine and the head is turned to one side and then the other inducing a transient horizontal nystagmus that changes direction based on the side of the head turn. In the most common form of horizontal canal BPPV, a head turn to the right leads to right-beating nystagmus, whereas a head turn to the left leads to left-beating nystagmus (the abnormal side is the side with the more intense nystagmus). In the less common form of horizontal canal BPPV, the nystagmus beats in the direction opposite the head turn.

\section{Gait and balance testing}

The patient is observed while walking normally, while walking in tandem, and in the Romberg position with eyes opened and closed. Impaired gait and balance can accompany dizziness of any cause but as a general rule severe gait impairment suggests a neurologic disorder. 
Figure 2 The Dix-Hallpike test and the canalith repositioning maneuver
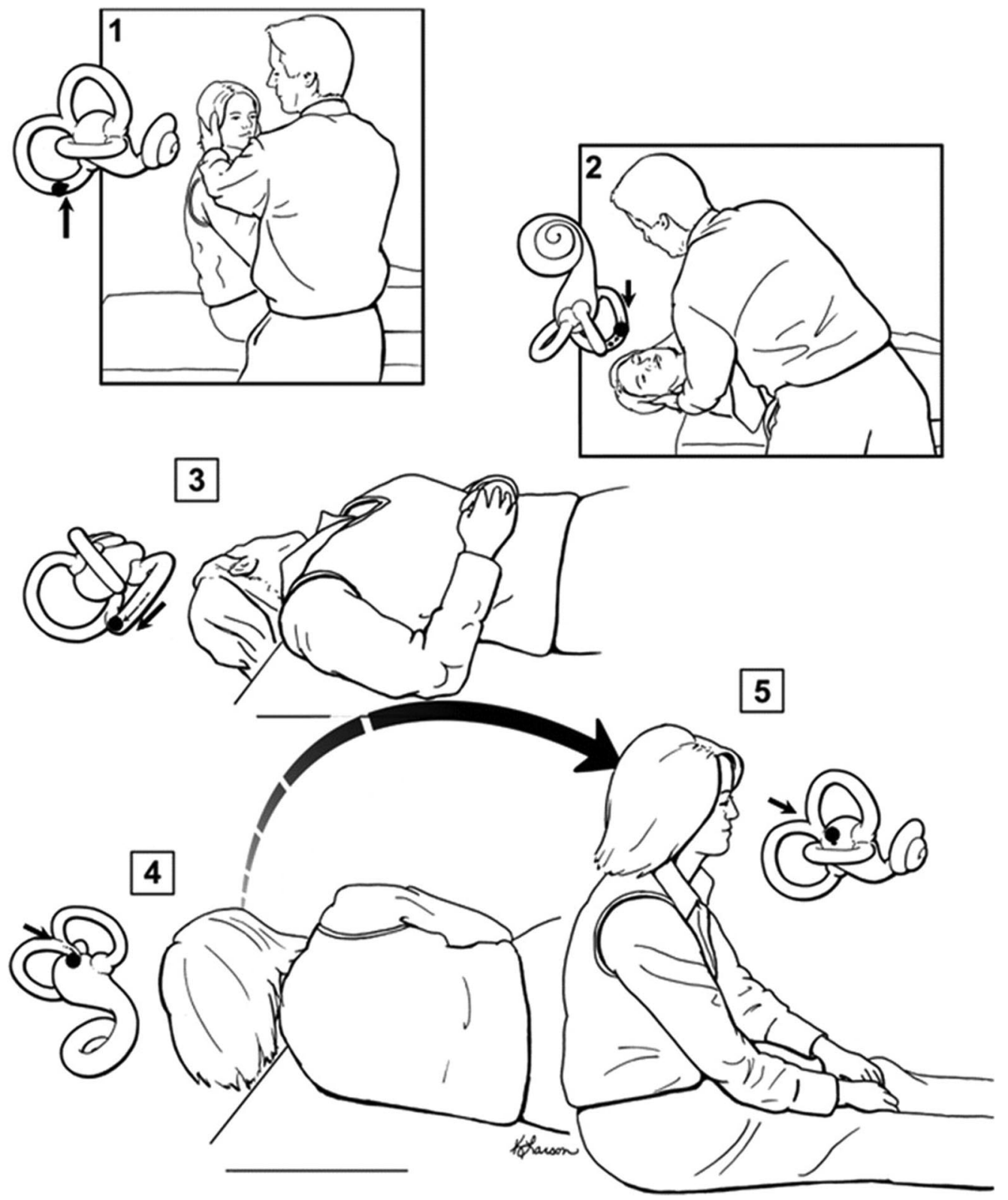

The Dix-Hallpike test is performed by turning the patient's head about 45 degrees toward the side to be tested (step 1) and then laying the patient down quickly (step 2). If BPPV is present, nystagmus ensues usually within seconds. The patient is held in the right head-hanging position (step 2) for 20 to 30 seconds, and then the remaining steps of the canalith repositioning maneuver can be performed (steps 3-5). In step 3, the head is turned 90 degrees toward the unaffected side. Step 3 is held for 20 to 30 seconds before turning the head another 90 degrees (step 4) so the head is nearly in the face-down position. Step 4 is held for 20 to 30 seconds, and then the patient is brought quickly back up to the sitting up position. The movement of the otolith material within the labyrinth is depicted with each step, showing how otoliths are moved from the posterior semicircular canal to the vestibule. From: Fife T, Iverson T, Lempert J, et al. Practice parameter: therapies for benign paroxysmal positional vertigo. Neurology 2008;70:2067-2074.

Patients with peripheral vestibular lesions (labyrinth and eighth nerve) are off-balance but usually can walk with assistance. Patients with peripheral neuropathy or bilateral vestibulopathy may be unable to stand in the Romberg position with eyes closed.

Common dizziness presentations Acute prolonged severe dizziness Patients who present with new onset severe dizziness, imbalance, and nausea and vomiting are espe- 
cially challenging because serious neurologic causes such as brainstem and cerebellar stroke must be considered. ${ }^{3}$ Which patients need to undergo immediate neuroimaging and which patients can be reassured and managed conservatively? Although no validated tool has been developed to provide support for this decision, the finding of unidirectional horizontal spontaneous nystagmus and a corresponding positive head thrust test in a patient without other neurologic symptoms and signs suggests a peripheral vestibular lesion, usually vestibular neuritis, a presumed viral inflammation of the vestibular nerve. ${ }^{4} \mathrm{~A}$ patient with vestibular neuritis on the right side will have spontaneous left-beating nystagmus and a positive head thrust test to the right side. The presence of vascular risk factors, associated neurologic symptoms, direction-changing nystagmus, or absent head thrust sign increases the likelihood of a central lesion. The optimal selection of patients for MRI is not completely clear, and currently is influenced by the preferences of the physician and patient. One should keep in mind that MRI can miss small infarcts in the posterior fossa.

Recurrent spontaneous attacks of dizziness When assessing patients with recurrent attacks of dizziness, clinicians have the "bonus" information of the natural history of the disorder. A patient with isolated recurrent attacks of dizziness occurring over many months or years is unlikely to have a sinister central cause. Transient ischemic attacks (TIAs) in the posterior circulation should be considered when the recurrent attacks are recent in onset and of short duration (minutes), particularly when accompanied by other neurologic signs or symptoms. Occasionally, dizziness can be the only symptom of a TIA but repeated episodes of dizziness over many months without associated neurologic symptoms would be highly atypical for TIAs. Of note, auditory symptoms can accompany central ischemic events if the anterior inferior cerebellar artery is involved. Ménière disease is characterized by recurrent dizziness with associated auditory symptoms, fluctuating hearing loss, ear fullness, and tinnitus. Migraine-associated dizziness occurs with or without a headache. ${ }^{5}$ Recurrent spontaneous dizziness attacks that are not associated with auditory or neurologic symptoms over time are most likely migrainous in origin. Very brief spontaneous vertigo episodes, often labeled "vestibular paroxysmia," may be caused by a mechanism analogous to that of hemifacial spasm or trigeminal neuralgia.

Recurrent positionally triggered dizziness Two of the most common causes of dizziness are positionally triggered: orthostatic hypotension and BPPV. BPPV is typically triggered by lying down, rolling over in bed, or looking up to reach for something. By contrast, dizziness associated with orthostatic hypotension is triggered by getting up from a sitting or lying position and is relieved by lying down. The diagnosis of BPPV is confirmed by the Dix-Hallpike test while the diagnosis of orthostatic hypotension is made if symptoms and a drop in blood pressure occur after standing. Variants of BPPV include cupulolithiasis (particles adherent to the cupula), particles plugging the canal, and particles in other affected canals. The symptoms are similar to those of the usual posterior canal variant of BPPV but the dizziness lasts longer and the

Chronic persistent dizziness and imbalance associated with movement-induced oscillopsia should raise suspicion for bilateral vestibulopathy, which can be readily identified at the bedside by a head thrust test that is positive to both sides. 


\section{Because symptoms are subjective, defining the characteristics (e.g., onset, triggers, duration) of the symptom may be more important than defining the actual symptom. Patients tend to be more reliable and consistent with this information, which is critical to formulating the differential diagnosis.}

positional nystagmus has different characteristics. As noted earlier, central lesions can also present with positional dizziness but the pattern of induced nystagmus is also different, usually persistent downbeat.

Chronic persistent dizziness Anxiety disorders commonly present with chronic continuous dizziness. ${ }^{6}$ Patients often do not recognize the interrelationship of the dizziness and anxiety symptoms. Chronic persistent dizziness and imbalance associated with movement-induced oscillopsia should raise suspicion for bilateral vestibulopathy, which can be readily identified at the bedside by a head thrust test that is positive to both sides. Patients with a bilateral vestibulopathy will have substantial disability if it is acute in onset, such as with gentamicin ototoxicity. However, a patient with gradual progressive bilateral vestibulopathy may report only mild nonspecific symptoms of dizziness. Mal de debarquement is a dizziness syndrome characterized by a continuous perception of rocking, bobbing, or swaying, as if on a boat. The syndrome is typically preceded by a boat or airplane trip and remarkably patients feel better when they are in motion such as riding in an automobile. Cerebellar ataxia syndromes can present with subacute (e.g., paraneoplastic disorders) or chronic (e.g., spinocerebellar ataxia) dizziness. These disorders are generally readily identifiable based on appendicular or truncal ataxia and central eye movement abnormalities such as saccadic intrusions, impaired smooth pursuit, gaze-evoked nystagmus, or overshooting saccades.

\section{Management}

Treatment exists for most of the common causes of dizziness (table 2) although adequate randomized controlled treatment trials are sparse.

Patients with vestibular neuritis may benefit from a short course of high-dose oral corticosteroids. A randomized controlled study found patients treated with corticosteroids had an improved outcome on average compared with controls. ${ }^{7}$ However, the outcome was recovery of vestibular function as measured by caloric response at 1 year and thus the effect on symptomatic or functional outcome is unknown. Vestibular physical therapy can play an important role in the functional recovery of patients with vestibular neuritis. ${ }^{8}$

The posterior canal variant of BPPV is effectively treated with the canalith repositioning maneuver (figure 2). Two Class I and 3 Class II randomized controlled trials have been performed, which demonstrate the resolution of symptoms (measured at 1 day to 4 weeks) after one maneuver in $61 \%$ to $80 \%$ of treated patients compared with $10 \%$ to $48 \%$ of untreated patients. ${ }^{9}$ This degree of treatment benefit is among the largest effects achievable in clinical medicine. The benefit is particularly impressive because the outcome was cure as opposed to improvement or a surrogate measure. Strategies for the treatment of horizontal canal BPPV are also available, but less well tested.

In patients with Ménière disease, a destructive procedure of the affected vestibular apparatus, including vestibular nerve section or intratympanic gentamicin, can lead to the resolution of recur- 
rent vertigo attacks. However, only a small percentage of patients require surgery since the natural history of Ménière disease is such that spontaneous remissions are common and dizziness attacks often decline in frequency over time. Although salt restriction, diuretics, and other procedures are often used in patients with Ménière disease, high-level evidence to support these interventions is lacking.

The optimal management of patients with migraine-associated dizziness is yet to be adequately defined. These patients have a high rate of spontaneous improvement. ${ }^{10}$ Randomized controlled trials of migraine preventative medications have established efficacy for headache outcomes, but none have measured dizziness outcomes. Lifestyle changes that address stress management and aim to optimize sleep, exercise, and diet may be helpful but specific trials are also lacking.

\section{REFERENCES}

1. Eagles D, Stiell IG, Clement CM, et al. International survey of emergency physicians' priorities for clinical decision rules. Acad Emerg Med 2008;15:177-182.

2. Newman-Toker DE, Cannon LM, Stofferahn ME, Rothman RE, Hsieh YH, Zee DS. Imprecision in patient reports of dizziness symptom quality: a cross-sectional study conducted in an acute care setting. Mayo Clin Proc 2007;82:1329-1340.

3. Kerber KA, Brown DL, Lisabeth LD, Smith MA, Morgenstern LB. Stroke among patients with dizziness, vertigo, and imbalance in the emergency department: a population-based study. Stroke 2006;37: $2484-2487$.

4. Kattah JC, Talkad AV, Wang DZ, Hsieh YH, Newman-Toker DE. HINTS to diagnose stroke in the acute vestibular syndrome: three-step bedside oculomotor examination more sensitive than early MRI diffusion-weighted imaging. Stroke 2009;40:3504-510.

5. Neuhauser H, Lempert T. Vestibular migraine. Neurol Clin 2009;27:379-391.

6. Ruckenstein MJ, Staab JP. Chronic subjective dizziness. Otolaryngol Clin North Am 2009;42:71-77.

7. Strupp M, Zingler VC, Arbusow V, et al. Methylprednisolone, valacyclovir, or the combination for vestibular neuritis. N Engl J Med 2004;351:354-361.

8. Baloh RW, Kerber KA. Clinical Neurophysiology of the Vestibular System, 4th ed. Philadelphia: Oxford University Press; 2011.

9. Fife TD, Iverson DJ, Lempert T, et al. Practice parameter: therapies for benign paroxysmal positional vertigo (an evidence-based review): report of the Quality Standards Subcommittee of the American Academy of Neurology. Neurology 2008;70:2067-2074.

10. Neuhauser H, Radtke A, von Brevern M, Lempert T. Zolmitriptan for treatment of migrainous vertigo: a pilot randomized placebo-controlled trial. Neurology 2003;60:882-883.

\section{DISCLOSURES}

Dr. Kerber has served as a consultant for and received speaker honoraria from the American Academy of Neurology; receives publishing royalties for Clinical Neurophysiology of the Vestibular System, 4th edition (Oxford University Press, 2010); and receives research support from the NIH/NCRR and the Agency for Healthcare Research and Quality. Dr. Baloh has received speaker honoraria from the American Academy of Neurology; serves on the editorial board of Neurology ${ }^{\circledR}$; receives publishing royalties for Clinical Neurophysiology of the Vestibular System, 4th edition (Oxford University Press, 2010); and receives research support from the NIH. 


\section{Related articles from other AAN physician and patient resources}

Neurology ${ }^{\circledR} \quad \bullet \quad$ www.neurology.org

Book Review: Dizziness: A Practical Approach to Diagnosis and Management. June 16, 2009;72:2139.

Pearls \& Oy-sters: Vestibular neuritis or not? The significance of head tilt in a patient with rotatory vertigo.

May 19, 2009;72:e101-e102.

Neurology Now $^{\circledR}$

- www.neurologynow.org

Spin doctors.

September/October 2007;3:13-14.

Neurology Today ${ }^{\circledR} \quad$ www.neurotodayonline.com

Letter to the Editor: Report on balance is unbalanced.

February 18, 2010;10:4. 


\section{Neurology ${ }^{\circ}$ Clinical Practice}

The evaluation of a patient with dizziness

Kevin A. Kerber and Robert W. Baloh

Neurol Clin Pract 2011;1;24-33

DOI 10.1212/CPJ.0b013e31823d07b6

This information is current as of December 1, 2011

\section{Updated Information \& Services}

\section{Supplementary Material}

References

Citations

Subspecialty Collections

Permissions \& Licensing

Reprints including high resolution figures, can be found at: http://cp.neurology.org/content/1/1/24.full.html

Supplementary material can be found at: http://cp.neurology.org/content/suppl/2012/04/09/1.1.24.DC1

This article cites 9 articles, 4 of which you can access for free at: http://cp.neurology.org/content/1/1/24.full.html\#\#ref-list-1

This article has been cited by 1 HighWire-hosted articles: http://cp.neurology.org/content/1/1/24.full.html\#\#otherarticles

This article, along with others on similar topics, appears in the following collection(s):

All Clinical Neurology

http://cp.neurology.org//cgi/collection/all_clinical_neurology All Neurotology

http://cp.neurology.org//cgi/collection/all_neurotology

Clinical neurology examination

http://cp.neurology.org//cgi/collection/clinical_neurology_examination Vertigo

http://cp.neurology.org//cgi/collection/vertigo

Information about reproducing this article in parts (figures,tables) or in its entirety can be found online at:

http://cp.neurology.org/misc/about.xhtml\#permissions

Information about ordering reprints can be found online: http://cp.neurology.org/misc/addir.xhtml\#reprintsus

Neurol Clin Pract is an official journal of the American Academy of Neurology. Published continuously since 2011, it is now a bimonthly with 6 issues per year. Copyright Copyright $\odot 2011$ by AAN Enterprises, Inc.. All rights reserved. Print ISSN: 2163-0402. Online ISSN: 2163-0933.

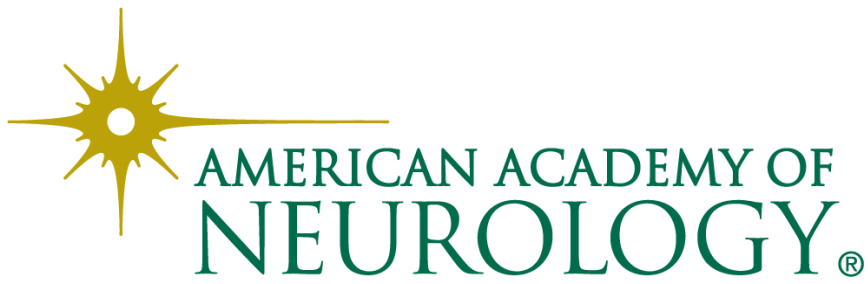

